\title{
全对称构型金属支撑固体氧化物燃料电池
}

\author{
周玉存, 叶晓峰, 王绍荣 \\ (中国科学院 上海硅酸盐研究所, 上海 200050)
}

摘 要: 与传统的全陶瓷结构的固体氧化物燃料电池(Solid Oxide Fuel Cell, SOFC)相比, 金属支撑固体氧化物燃料 电池(MS-SOFCs) 具有材料成本低, 结构稳定性高, 抗热震性高等优点。为了促进 SOFC 的商业化, 采用流延-烧结浸渗工艺制备了 $\mathrm{Ce}_{0.8} \mathrm{Sm}_{0.2} \mathrm{O}_{2-\delta}(\mathrm{SDC})-430 \mathrm{~L}$ 阳极 $/ \mathrm{Zr}_{0.88} \mathrm{Sc}_{0.22} \mathrm{Ce}_{0.01} \mathrm{O}_{2.12}(\mathrm{SSZ})$ 电解质/SDC-430L 阴极构型的全对称结构 金属支撑固体氧化物燃料电池(MS-SOFC)。电池以湿氢气为燃料、空气为氧化气，在 $600 、 650$ 和 $700^{\circ} \mathrm{C}$ 时的最大 功率密度为 $220 、 250$ 和 $280 \mathrm{~mW} / \mathrm{cm}^{2}$ 。电化学阻抗谱的测试表明, 电池的性能由 SDC-430L 电极的极化阻抗所主导, 在 700、650 和 $600^{\circ} \mathrm{C}$ 时，电池欧姆阻抗分别为 $0.16 、 0.21$ 和 $0.29 \Omega \cdot \mathrm{cm}^{2}$ ，极化阻抗分别为 $0.67 、 0.90$ 和 $1.22 \Omega \cdot \mathrm{cm}^{2}$ 。 与阳极相比，阴极的极化阻抗更为显著。对称 SDC-430L 电池在 $3 \% \mathrm{H}_{2} \mathrm{O}-97 \% \mathrm{H}_{2}$ 和空气气氛中测得的极化阻抗分别 为 0.23 和 $1.92 \Omega \cdot \mathrm{cm}^{2}\left(650^{\circ} \mathrm{C}\right.$ )。进一步优化电池结构(例如采用更加精细的 $430 \mathrm{~L}$ 骨架)和催化材料(例如含有 $\mathrm{Ag} 、 \mathrm{Pt}$ 的复合材料)将有助于提升该 MS-SOFC 的电化学性能。

关 键 词: 金属支撑; 固体氧化物燃料电池; 氧化铈

中图分类号: TQ174 文献标识码: A

\section{All Symmetrical Metal Supported Solid Oxide Fuel Cells}

\author{
ZHOU Yu-Cun, YE Xiao-Feng, WANG Shao-Rong \\ (Shanghai Institute of Ceramics, Chinese Academy of Sciences, Shanghai 200050, China)
}

\begin{abstract}
Metal-supported solid oxide fuel cells (MS-SOFCs) have many advantages like low materials cost, excellent structural stability and high tolerance toward rapid thermal cycling over the traditional all ceramic SOFCs. To facilitate the commercialization of SOFCs, an all symmetrical MS-SOFC with the structure of $\mathrm{Ce}_{0.8} \mathrm{Sm}_{0.2} \mathrm{O}_{2-\delta}$ (SDC)-430L anode/ $\mathrm{Zr}_{0.88} \mathrm{Sc}_{0.22} \mathrm{Ce}_{0.01} \mathrm{O}_{2.12}$ (SSZ) electrolyte/SDC-430L cathode was developed by a tape casting- sintering-infiltration method. When measured in humidified hydrogen fuel and air oxidant, the maximum power densities (MPD) of the fuel cell are 220,250 and $280 \mathrm{~mW} / \mathrm{cm}^{2}$ at 600,650 and $700^{\circ} \mathrm{C}$, respectively. Electrochemical impedance spectra measurement shows that the cell performances are primarily dominated by polarization resistances derived from the SDC-430L electrodes. The pure ohmic resistances are $0.16,0.21$ and $0.29 \Omega \cdot \mathrm{cm}^{2}$ and the polarization resistances are $0.67,0.90$ and $1.22 \Omega \cdot \mathrm{cm}^{2}$ at 700,650 and $600{ }^{\circ} \mathrm{C}$, respectively. Compared with that of the anode, polarization resistance of cathode is much higher. When measured at $650^{\circ} \mathrm{C}$, polarization resistances of the symmetrical SDC-430L cell are 0.23 and $1.92 \Omega \cdot \mathrm{cm}^{2}$ in $3 \% \mathrm{H}_{2} \mathrm{O}-97 \% \mathrm{H}_{2}$ and air, respectively. Further optimizing the cell structure (e.g., applying a finer $430 \mathrm{~L}$ backbone) and the catalyst materials (e.g., Ag, Pt containing composite materials) may enhance the electrochemical performances of such MS-SOFC.
\end{abstract}


Key words: metal supported; solid oxide fuel cell; ceria

固体氧化物燃料电池 (SOFC) 是一种能量转化 装置, 它可通过电化学反应直接将燃料(如氢气和 甲烷)的化学能转化为电能, 具有燃料来源广、能量 转化效率高、环境友好等优点，在固定式发电系统、 家用热电联供系统等领域具有广泛的用途 ${ }^{[1-3]}$ 。

金属支撑型固体氧化物燃料电池(MS-SOFC)用 廉价的金属(例如不锈钢)来替代传统 SOFC 中大部 分的陶瓷材料, 从而可以显著改善电池的机械强度, 提高电池的抗热震性和抗氧化还原循环能力, 降低 原材料成本和加工成本 ${ }^{[4-8]}$ 。但是将金属材料引入到 SOFC 中又会给电池的制备和运行带来很多的困难, 比如电解质难以致密化, 阳极和支撑体间发生元素 扩散及阴极制备困难等问题[9-11]。为了解决 MS-SOFC 的制备困难, 提高其电化学性能和长期稳定性, 文 献[12-14]采用 “流延-共烧结” 工艺制备了多孔 430L 不锈钢支撑体/氧化钎稳定氧化锆(YSZ)电解质/多孔 YSZ 电池骨架, 而后采用化学浸渗工艺在多孔 430L 中低温制备阳极活性材料, 在多孔 YSZ 中制备阴极 活性材料。该工艺将电池骨架材料的制备和电极活性 材料的制备有效分开，克服了电解质的致密化、阳极 的元素扩散及阴极的制备困难, 制备的 MS- SOFC 具 有优异的电化学性能和长期稳定性 ${ }^{[15-16]}$ 。

上述研究是将 $430 \mathrm{~L}$ 置于电池阳极侧, 作为电 池的支撑体和阳极。在前面工作的基础上, 本工作 将 430L 应用到电池的阴极侧, 制备电极材料-多孔 $430 \mathrm{~L} /$ 氧化钪稳定氧化锆(SSZ) 电解质/电极材料-多 孔 430L 对称构型的 MS-SOFC。该结构的构筑最大 限度地降低了陶瓷氧化物材料的使用。在该对称结 构中, 电极骨架材料均为 430L 不锈钢, 整个电池中 仅剩下中间一层厚度在 $20 \mu \mathrm{m}$ 左右的电解质为稀土 氧化物材料。430L 不锈钢在本结构中具有三个功能: (1)作为电池的支撑层, 提供整个电池的强度; (2)作 为电极的骨架层, 提供电极催化剂材料的载体; (3)作 为电池阴阳极的电子传输通道, 促进电化学反应并 收集电流。由于不锈钢材料价格低廉、强度好、热 导率和电导率高, 该对称构型 MS-SOFC 的开发将有 效降低 SOFC 的原料和加工成本, 制得的 MS-SOFC 有望获得较好的电化学性能、力学强度和热震性等。

\section{1 实验方法}

\section{1 电池制备}

多孔430L/致密 SSZ电解质/多孔430L电池骨架
的制备：以 $\mathrm{SSZ}$ 粉体 $\left(\mathrm{Zr}_{0.88} \mathrm{Sc}_{0.22} \mathrm{Ce}_{0.01} \mathrm{O}_{2.12}\right.$, 日本第 一稀元素)、不锈钢 $430 \mathrm{~L}$ 粉体(400目, 石家庄京元粉 末材料有限责任公司)和一水合草酸铵(造孔剂, 国 药集团化学试剂有限公司)为原料, 采用流延成型 工艺经球磨、脱泡、流延过程, 分别制备SSZ电解质 膜片和430L电极膜片，采用热压工艺制备 “430L/ $\mathrm{SSZ} / 430 \mathrm{~L}$ ”三层结构 $\left(3000 \mathrm{psi}, 75^{\circ} \mathrm{C}, 10 \mathrm{~min}\right)$ 。将层 压好的素坏剪裁成圆片 $(\phi 19 \mathrm{~mm})$, 再在 $5 \% \mathrm{H}_{2}-95 \%$ $\mathrm{N}_{2}$ 气氛中 $1300^{\circ} \mathrm{C}$ 烧结 $4 \mathrm{~h}$ 即可得到上述电池骨架。

$\mathrm{Ce}_{0.8} \mathrm{Sm}_{0.2} \mathrm{O}_{2-\delta}$ (SDC)-430L复合电极的制备：以 硝酸钐 $\left(\mathrm{Sm}\left(\mathrm{NO}_{3}\right)_{3}\right.$, 国药集团化学试剂有限公司)和 硝酸亚铈 $\left(\mathrm{Ce}\left(\mathrm{NO}_{3}\right)_{3}\right.$, 国药集团化学试剂有限公司 $)$ 为原料, 按照 $n(\mathrm{Sm}): n(\mathrm{Ce})=2: 8$ 配制 $\mathrm{SDC}$ 水溶液, $\mathrm{SDC}$ 的浓度为 $3 \mathrm{~mol} / \mathrm{L}$ 。采用化学浸渗的方法将该溶液浸 渗到电解质两侧的多孔 $430 \mathrm{~L}$ 中, 干燥后在空气中 $350{ }^{\circ} \mathrm{C}$ 热处理 $2 \mathrm{~h}$ 使硝酸盐分解即可得到 $\mathrm{SDC}-430 \mathrm{~L}$ 复合电极。浸渗-热处理工艺需要重复数次, 以满足 所需的浸渗量 $(10 \mathrm{wt} \%)$ 。每个 “浸渗一热处理” 过程 可引入 $\mathrm{SDC}$ 的量约为 $2 \mathrm{wt} \% \sim 3 \mathrm{wt} \%$ 。

\section{2 电池性能及结构表征}

采用银浆(DAD-87, 上海合成树脂研究所)作为 密封材料将电池密封在氧化铝陶瓷管一端, 电极两 侧用银网收集电流，银丝作为导线。整个陶瓷装置 置于电炉中进行测试，陶瓷管内侧通燃料气，陶瓷 管外侧通空气。采用四端子法, 利用电化学工作站 (IM6, 德国ZAHNER)测量电池的电流-电压 $(I-V)$ 曲 线和开路状态 $(\mathrm{OCV})$ 下的电化学阻抗谱(EIS)。阻抗 谱的测试频率范围为 $0.1 \mathrm{~Hz} 10 \mathrm{MHz}$, 偏压振幅为 $20 \mathrm{mV}$ 。阻抗谱与实轴的高频弧截距为电池欧姆阻 抗 $\left(R_{\mathrm{o}}\right)$, 阻抗谱与实轴的低频弧截距为电池的总阻 抗 $\left(R_{\mathrm{t}}\right)$, 阻抗谱与实轴的低频和高频截距的差值为 电池极化阻抗 $\left(R_{\mathrm{p}}\right)$ 。

采用扫描电镜(SEM, Hitachi S-4800-II)观察电 池的截面和电极微结构。采用德国Bruker公司的D8 ADVANCE型X射线衍射仪 $(\mathrm{CuK} \alpha$ 靶)对粉体的相结 构进行分析。

\section{2 结果与讨论}

图 1 是采用流延一烧结工艺制得的多孔 430L/致密 SSZ 电解质/多孔 $430 \mathrm{~L}$ 对称构型的 MS-SOFC 骨架(未 浸渍 SDC 电极材料)的 SEM 照片。如图 1(a)所示, 从 左到右分别是作为电池阴极骨架的 $430 \mathrm{~L}$ 层 $(40 \mu \mathrm{m})$ 、 

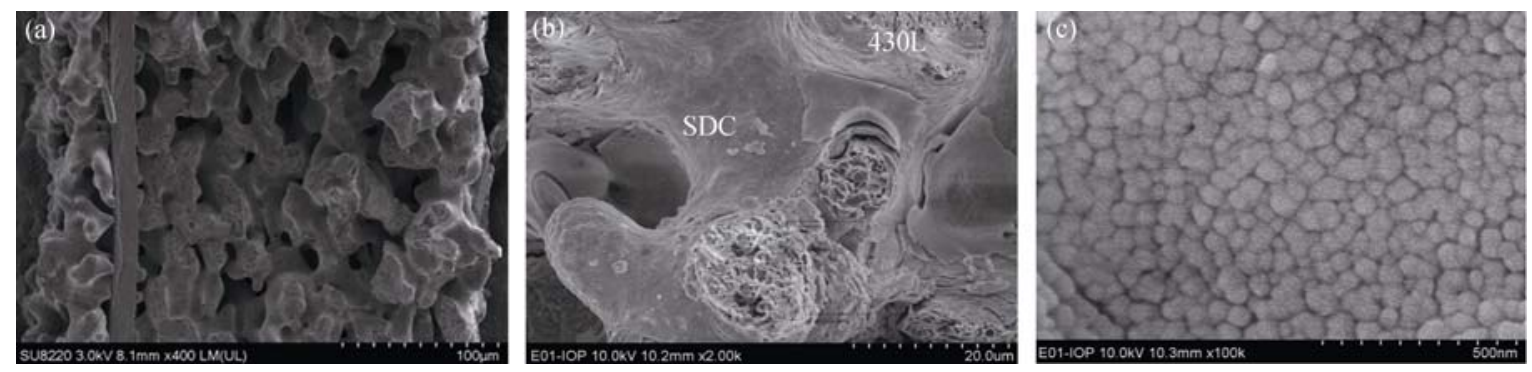

图 1 MS-SOFC 截面的 SEM 照片

Fig. 1 Cross-sectional SEM images of the MS-SOFC

(a) 430L/SSZ/430L backbone; (b) SDC-430L electrode; (c) Infiltrated SDC particles

SSZ 电解质层 $(20 \mu \mathrm{m})$ 和作为电池阳极骨架的 $430 \mathrm{~L}$ 层 $(230 \mu \mathrm{m})$, 电解质致密且与相邻的 $430 \mathrm{~L}$ 层结合紧 密。图 1(b)是单电池测试之后的 SDC-430L 的 SEM 照片, 可见 SDC 涂层均匀附着在 430L 骨架的空隙 处。图 1(c)是 SDC 涂层的高倍 SEM 照片, 可以看 出 SDC 呈现 “花椰菜” 结构: 10 20 nm 的 SDC 小 颗粒聚集而成直径为 50 100 nm 的 SDC 团聚体, 进 而形成 SDC 涂层。纳米尺度的 SDC 颗粒具有丰富 的比表面积, 有利于提高其催化活性。

图 2(a) 是制备的 SDC-430L/SSZ/SDC-430L 对称 构型的 MS-SOFC 在 $600 \sim 700^{\circ} \mathrm{C}$, 以 $3 \% \mathrm{H}_{2} \mathrm{O}-97 \% \mathrm{H}_{2}$ 为燃料, 空气为氧化气体 (流量均为 $100 \mathrm{sccm}$ ) 测得 的电压和功率密度随电流密度的变化曲线。电池在 600、650 和 $700^{\circ} \mathrm{C}$ 的最大功率密度(MPD) 分别为 $220 、 250$ 和 $280 \mathrm{~mW} / \mathrm{cm}^{2}$, 比 SDC-430L/YSZ/La ${ }_{0.6} \mathrm{Sr}_{0.4}$ $\mathrm{Fe}_{0.9} \mathrm{Sc}_{0.1} \mathrm{O}_{3-\delta}(\mathrm{LSFSc})-\mathrm{YSZ}$ 构型的 MS-SOFC 在 $700^{\circ} \mathrm{C}$ 获 得的 $550 \mathrm{~mW} / \mathrm{cm}^{2}$ 的功率密度低 ${ }^{[17]}$ 。由于两类电池的 阳极均为 SDC-430L, SDC-430L 阴极中 SDC 表面氧吸 附和交换能力的不足可能是导致本实验制得电池输 出功率较低的原因。图 2(b) 是制备的电池在 $O C V$ 下 测得的阻抗谱图, 从图中可见, 电池的总阻抗随着 温度的升高而降低, 且极化阻抗的变化要显著大于 欧姆阻抗。MS-SOFC 在 $700 、 650$ 和 $600^{\circ} \mathrm{C}$ 的欧姆 阻抗分别为 $0.16 、 0.21$ 和 $0.29 \Omega \cdot \mathrm{cm}^{2}$, 而极化阻抗 分别为 $0.67 、 0.90$ 和 $1.22 \Omega \cdot \mathrm{cm}^{2}$ (图 2(c)), 远大于 欧姆阻抗。由此可知, 极化阻抗主导着电池的性能, 进一步优化电极结构和电极材料可以提高其功率 输出。

为了进一步研究和区分电极阳极和阴极的性能, 实验还制备了对称电池并测试其在阳极和阴极工作 环境下的极化阻抗。图 3 是 SDC-430L/YSZ/SDC$430 \mathrm{~L}$ 对称电池在阳极和阴极气氛中测得的极化阻 抗值。 $650^{\circ} \mathrm{C}, \mathrm{SDC}-430 \mathrm{~L}$ 电极在空气中测得的极化 阻抗值 $\left(1.92 \Omega \cdot \mathrm{cm}^{2}\right)$ 要远大于在氢气中的极化阻抗 值 $\left(0.23 \Omega \cdot \mathrm{cm}^{2}\right)$, 因而电池的阴极极化阻抗主导着电
池的性能。从图 3 还可以看出阳极和阴极气氛下的 阻抗谱均由低频弧所主导, 而低频弧往往反映了电 极的表面过程，可见气体在 SDC-430L 电极表面的
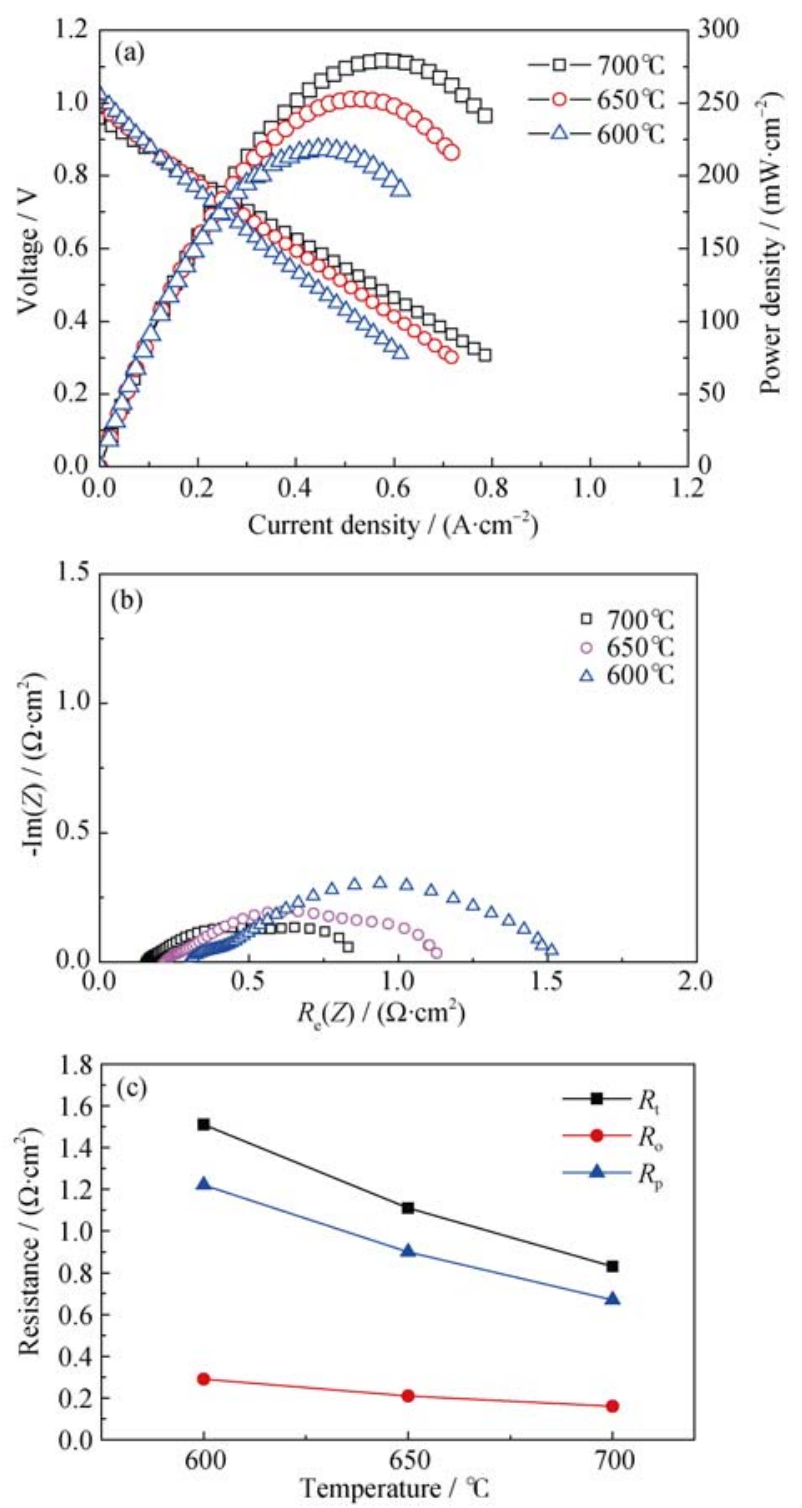

图 2 MS-SOFC 在 $600 \sim 700^{\circ} \mathrm{C}$ 的电化学性能

Fig. 2 Electrochemical characteristics of the MS-SOFC measured at $600-700^{\circ} \mathrm{C}$

(a) $I-P-V$ characteristics; (b) Impedance spectra; (c) $R_{\mathrm{t}}, R_{\mathrm{o}}$ and $R_{\mathrm{t}}$ measured at different temperatures 

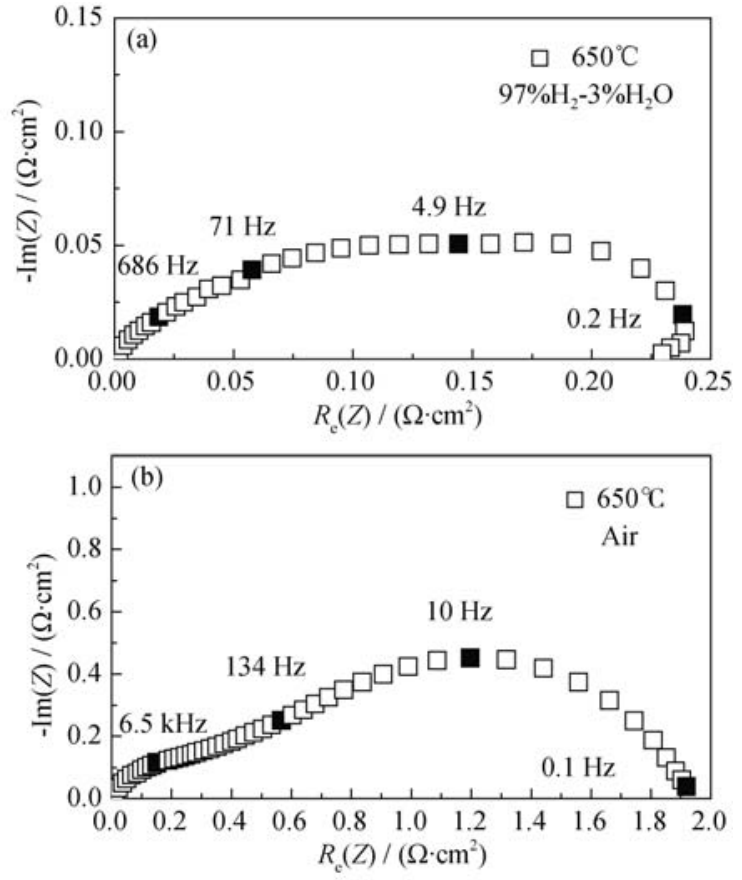

图 3 在(a) $97 \% \mathrm{H}_{2}-3 \% \mathrm{H}_{2} \mathrm{O}$ 和(b) 空气测试的对称电池极化阻 抗的阻抗图谱

Fig. 3 Impedance spectra of the polarization resistances of symmetrical cell measured in $97 \% \mathrm{H}_{2}-3 \% \mathrm{H}_{2} \mathrm{O}$ (a) and air (b)

扩散、吸附和解离过程较慢。进一步提高电池的性 能需要从以下两方面开展工作：(1)如图 1(a)所示, 不锈钢支撑体的颗粒及孔径都较大, 不利于反应活 性位的提高。因而需要进一步优化微观结构, 比如 降低支撑体的颗粒和孔径尺寸等; (2)考虑到 SDC 对 氧气还原和氢气氧化反应的催化活性还不够高, 可 以在 SDC 中引入 $\mathrm{Ag} 、 \mathrm{Pt}$ 等催化活性较高的材料, 构 建复合电极 ${ }^{[18-19]}$ 。

\section{3 结论}

采用流延-烧结-浸渗工艺制备的 SDC-430L/ SSZ/SDC-430L 全对称构型的 MS-SOFC, 电池在 600、 650 和 $700^{\circ} \mathrm{C}$ 的 $\mathrm{MPD}$ 分别为 $220 、 250$ 和 $280 \mathrm{~mW} / \mathrm{cm}^{2}$ 。 电池的性能由电极的极化阻抗所主导, 以 $700^{\circ} \mathrm{C}$ 为例，欧姆和极化阻抗分别为 0.16 和 $0.67 \Omega \cdot \mathrm{cm}^{2}$ 。 进一步研究发现该电极极化阻抗主要来源于电池 阴极。

\section{参考文献:}

[1] ORMEROD R M. Solid oxide fuel cells. Chemical Society Reviews, 2003, 32(1): 17-28.
[2] SINGHAL S C. Solid oxide fuel cells for stationary, mobile, and military applications. Solid State Ionics, 2002, 152: 405-410.

[3] MINH N Q. Solid oxide fuel cell technology — features and applications. Solid State Ionics, 2004, 174(1): 271-277.

[4] TUCKER M C. Progress in metal-supported solid oxide fuel cells: a review. Journal of Power Sources, 2010, 195(15): 4570-4582.

[5] LEAH R T, BRANDON N P, AGUIAR P. Modelling of cells, stacks and systems based around metal-supported planar IT-SOFC cells with CGO electrolytes operating at $500-600^{\circ} \mathrm{C}$. Journal of Power Sources, 2005, 145(2): 336-352.

[6] MATUS Y B, JONGHE L C D, JACOBSON C P, et al. Metalsupported solid oxide fuel cell membranes for rapid thermal cycling. Solid State Ionics, 2005, 176(5/6): 443-449.

[7] MALZBENDER J, WESSEL E, STEINBRECH R W. Reduction and re-oxidation of anodes for solid oxide fuel cells. Solid State Ionics, 2005, 176(29/30): 2201-2203.

[8] LEAH R, LANKIN M, BONE A, et al. Towards a fully REDOX stable SOFC: cell development at ceres power. ECS Transactions, 2013, 57(1): 849-856.

[9] FRANCO T, SCHIBINGER K, ILHAN Z, et al. Ceramic diffusion barrier layers for metal supported SOFCs. ECS Transactions, 2007, 7(1): 771-780.

[10] BRANDNE M, BRAM N, FROITZHEIM J, et al. Electrically conductive diffusion barrier layers for metal-supported SOFC. Solid State Ionics, 2008, 179(27-32): 1501-1504.

[11] NEDELEC R, NEAGU R, UHLENBRUCK S, et al. Gas phase deposition of diffusion barriers for metal substrates in solid oxide fuel cells. Surface \& Coatings Technology, 2011, 205(16): 3999-4004

[12] ZHOU YUCUN, YE XIAOFENG, LI JUNLIANG, et al. Metalsupported solid oxide fuel cells with a simple structure. Journal of The Electrochemical Society, 2014, 161(3): F332-F336.

[13] ZHOU YUCUN, MENG XIE, LIU XUEJIAO, et al. Novel architectured metal-supported solid oxide fuel cells with Mo-doped $\mathrm{SrFeO}_{3-\delta}$ electrocatalysts. Journal of Power Sources, 2014, 267: 148-154.

[14] ZHOU YUCUN, LIU XUEJIAO, LI JUNLIANG, et al. Novel metal-supported solid oxide fuel cells with impregnated symmetric $\mathrm{La}_{0.6} \mathrm{Sr}_{0.4} \mathrm{Fe}_{0.9} \mathrm{Sc}_{0.1} \mathrm{O}_{3-\delta}$ electrodes. Journal of Power Sources, 2014, 252: $164-168$.

[15] ZHOU YUCUN, HAN DA, YUAN CHUN, et al. Infiltrated $\mathrm{SmBa}_{0.5} \mathrm{Sr}_{0.5} \mathrm{Co}_{2} \mathrm{O}_{5+\delta}$ cathodes for metal-supported solid oxide fuel cells. Electrochimica Acta, 2014, 149: 231-236.

[16] ZHOU YUCUN, CHEN TING, LI JUNLIANG, et al. Longterm stability of metal-supported solid oxide fuel cells employing infiltrated electrodes. Journal of Power Sources, 2015, 295: 67-73.

[17] ZHOU YUCUN, LUO TING, DU XIANLONG, et al. High activity of nanoporous- $\mathrm{Sm}_{0.2} \mathrm{Ce}_{0.8} \mathrm{O}_{2-\delta} @ 430 \mathrm{~L}$ composites for hydrogen electro-oxidation in solid oxide fuel cells. Advanced Energy Materials, 2014, 4: 1400883-1-5.

[18] ADIJANTO L, SAMPATH A, YU A.S, et al. Synthesis and stability of $\mathrm{Pd} @ \mathrm{CeO}_{2}$ core-shell catalyst films in solid oxide fuel cell anodes. ACS Catalysis, 2013, 3(8): 1801-1809.

[19] SENGODAN S, CHOI S, JUN A, et al. Layered oxygen-deficient double perovskite as an efficient and stable anode for direct hydrocarbon solid oxide fuel cells. Nat. Mater, 2015, 14(2): 205-209. 